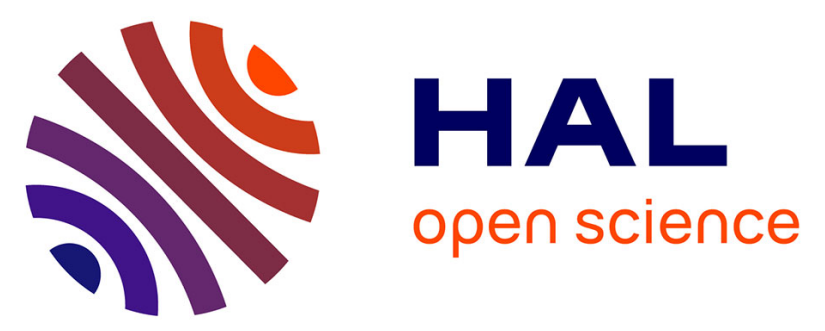

\title{
Ever-Evolving Identity of Magnetic Nanoparticles within Human Cells, the Interplay of Endosomal Confinement, Degradation, Storage, and Neo-Crystallization
}

Aurore van de Walle, Jelena Kolosnjaj-Tabi, Yoann Lalatonne, Claire Wilhelm

\section{- To cite this version:}

Aurore van de Walle, Jelena Kolosnjaj-Tabi, Yoann Lalatonne, Claire Wilhelm. Ever-Evolving Identity of Magnetic Nanoparticles within Human Cells, the Interplay of Endosomal Confinement, Degradation, Storage, and Neo-Crystallization. Accounts of Chemical Research, 2020, 53 (10), pp.2212-2224. 10.1021/acs.accounts.0c00355 . hal-03038294

\section{HAL Id: hal-03038294 https://hal.science/hal-03038294}

Submitted on 3 Dec 2020

HAL is a multi-disciplinary open access archive for the deposit and dissemination of scientific research documents, whether they are published or not. The documents may come from teaching and research institutions in France or abroad, or from public or private research centers.
L'archive ouverte pluridisciplinaire HAL, est destinée au dépôt et à la diffusion de documents scientifiques de niveau recherche, publiés ou non, émanant des établissements d'enseignement et de recherche français ou étrangers, des laboratoires publics ou privés. 


\section{Ever-Evolving Identity of Magnetic Nanoparticles within Human Cells, the Interplay of Endosomal Confinement, Degradation, Storage, and Neo-Crystallization}

Aurore Van de Walle ${ }^{++}$, Jelena Kolosnjaj-Tabi ${ }^{\S+}$, Yoann Lalatonne ${ }^{\perp \|}$, Claire Wilhelm ${ }^{+*}$

†. Laboratoire Matière et Systèmes, Complexes MSC, UMR 7057, CNRS \& University of Paris, 75205, Paris Cedex 13, France

\&Institute of Pharmacology and Structural Biology, 205 Route de Narbonne, 31400 Toulouse, France

$\perp$ Inserm, U1148, Laboratory for Vascular Translational Science, Université Paris 13, Sorbonne Paris Cité, F-93017 Bobigny, France

" Services de Biochimie et Médecine Nucléaire, Hôpital Avicenne Assistance PubliqueHôpitaux de Paris F-93009 Bobigny, France.

${ }^{+}$Equal contribution

*claire.wilhelm@univ-paris-diderot.fr

\section{CONSPECTUS}

Considerable knowledge has been acquired in inorganic nanoparticles synthesis and nanoparticles potential use in biomedical applications. Among different materials, iron oxide nanoparticles remain unrivaled for several reasons. Not only they respond to multiple physical stimuli (e.g. magnetism, light) and they exert multifunctional therapeutic and diagnostic actions, but also they are biocompatible, and they integrate endogenous iron-related metabolic pathways. With the aim to optimize the use of (magnetic) iron oxide nanoparticles in biomedicine, different bio-physical phenomena have been recently identified and studied. Among them, the concept of "nanoparticle's identity" is of particular importance. Nanoparticles identities evolve in distinct biological environments and over different periods of time. In this account, we focus on the remodeling of magnetic nanoparticles identity following nanoparticles journey inside the cells. For instance, nanoparticles functions, such as heat generation or magnetic resonance imaging, can be highly impacted by endosomal confinement. Structural degradation of nanoparticles was also evidenced and quantified in cellulo and correlates with the loss of nanoparticles magnetic properties. Remarkably, in human stem cells, the nonmagnetic products of nanoparticles degradation could be subsequently reassembled into neosynthetized, endogenous magnetic nanoparticles. This stunning occurrence might account for magnetic particles naturally found in human organs, especially the brain. However, mechanistic details and the implication of such phenomena in homeostasis and disease have yet to be completely unraveled. 
This Account aims to assess the short and the long-term transformations of magnetic iron oxide nanoparticles in living cells, particularly focusing on human stem cells. Precisely, we herein overview the multiple and ever-evolving chemical, physical and biological magnetic nanoparticles identities and emphasize the remarkable intracellular fate of these nanoparticles.

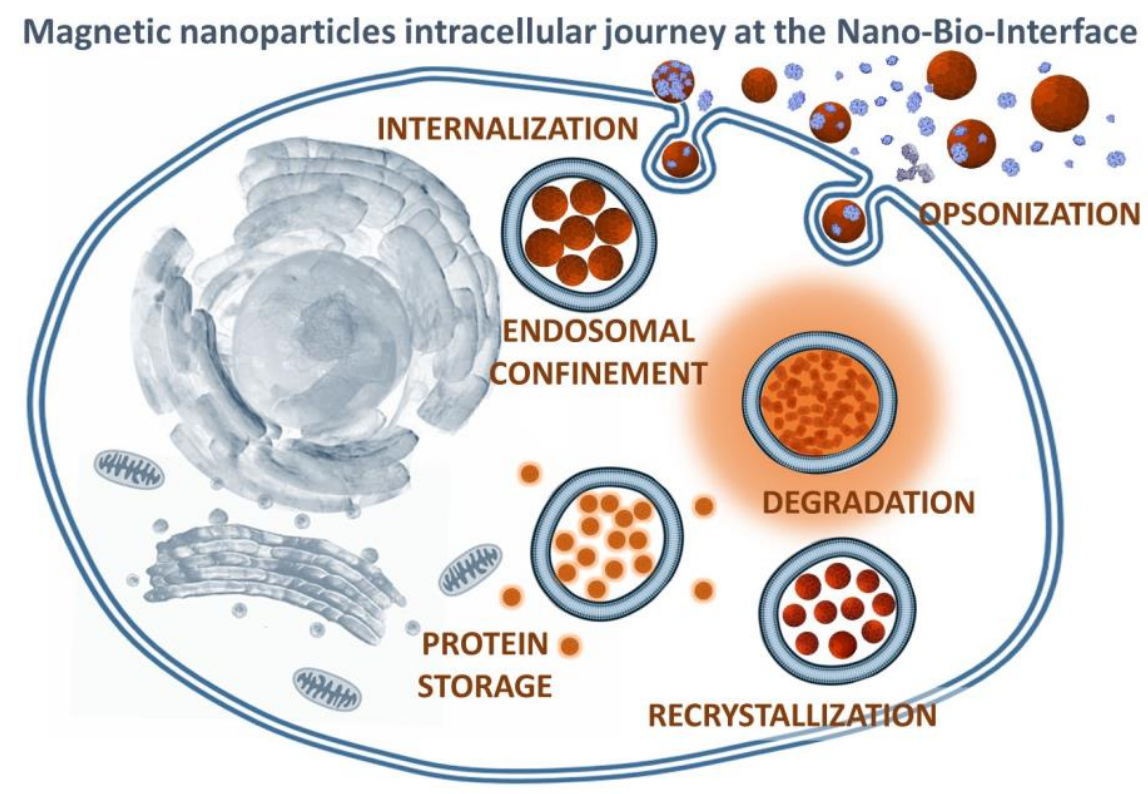

\section{KEY REFERENCES}

- Van de Walle, A.; Fromain, A.; Sangnier, A. P.; Curcio, A.; Lenglet, L.; Motte, L.; Lalatonne, Y.; Wilhelm, C., Real-Time in Situ Magnetic Measurement of the Intracellular Biodegradation of Iron Oxide Nanoparticles in a Stem Cell-Spheroid Tissue Model. Nano Research 2020, 13, 467-476. ${ }^{1}$ This work evidenced that magnetic nanoparticles can be totally degraded in mesenchymal stem cells and that this degradation can be measured magnetically, in real-time, on living cells.

- Van de Walle, A.; Sangnier, A. P.; Abou-Hassan, A.; Curcio, A.; Hémadi, M.; Menguy, N.; Lalatonne, Y.; Luciani, N.; Wilhelm, C., Biosynthesis of Magnetic Nanoparticles from NanoDegradation Products Revealed in Human Stem Cells. Proceedings of the National Academy of Sciences 2019, 116 (10), 4044-4053.2 This work evidenced that stem cells can "remagnetize" after degrading magnetic nanoparticles, mirroring the neosynthesis of nanoparticles.

- Curcio, A.; Van de Walle, A.; Serrano, A.; Preveral, S.; Péchoux, C.; Pignol, D.; Menguy, N.; Lefèvre, C. T.; Espinosa, A.; Wilhelm, C., Transformation Cycle of Magnetosomes in Human Stem Cells: From Degradation to Biosynthesis of Magnetic Nanoparticles Anew. ACS nano 2019, 14, 1406-1417..$^{3}$ This work showed that biogenic magnetosomes made by bacteria can be re-processed by human cells; they can be degraded and recrystallized into magnetic nanoparticles anew.

- Mary, G.; Van de Walle, A.; Perez, J. E.; Ukai, T.; Maekawa, T.; Luciani, N.; Wilhelm, C., High-Throughput Differentiation of Embryonic Stem Cells into Cardiomyocytes with a Microfabricated Magnetic Pattern and Cyclic Stimulation. Advanced Functional Materials 2020, 2002541. ${ }^{4}$ This work demonstrated that magnetic nanoparticles combined with electromagnetic stimulation can support enhanced differentiation of pluripotent embryonic stem cells. 


\section{INTRODUCTION}

Nanomedicine emerged in an attempt to overcome the limitations of conventional therapeutic and diagnostic approaches. Nanoparticles might, for instance, serve as carriers to deliver active ingredients to the target site, which could result in therapy improvement. In terms of diagnosis, nanoparticles might not only detect anomalous tissues, but also discerern abnormal cells or precancerous lesions. In addition, inorganic nanoparticles could be used as physical mediators to treat malignancies upon remote activation with light, magnetism or electric field. These remote triggers induce in turn a physical effect (e.g. heat, movement, force) via nanoparticles located in situ, resulting in a precise temporal and spatial control of the treatment. Such physical approaches are currently being tested in clinical trials (such as Aurolase $\AA^{8}$ therapy, mediated by AuroShell囚 nanoparticles made of a gold nanoshell) or received European market approval as a medical device (such as NBTXR3®, hafnium oxide nanoparticles, which locally increase the radiation dose). Notwithstanding these novel developments, magnetic iron oxide nanoparticles were the first and the only inorganic nanoparticle-based drugs (marketed as Feridex $\AA($ Endorem $\AA)$, and Resovist ${ }^{\circledR}\left(\right.$ Cliavist $\left.{ }^{\circledR}\right)$ ) that obtained the marketing authorization as medicinal products and became largely available over the globe.

The ease to synthesize and functionalize iron oxide nanoparticles, their potential as multifunctional therapeutics (e.g. hyperthermia or drug delivery agents) or diagnostic tools (e.g. magnetic resonance contrast agents), the possibility to magnetically guide them, as well as their advantage of being biocompatible, make them particularly attractive for nanomedicine..$^{5-9}$ Moreover, iron oxides are being increasingly envisaged as cues to regulate intracellular biological processes, or tools for intracellular cargo delivery. ${ }^{10,11}$ In regenerative medicine, nanotechnology deployed additional therapeutic assets to repair damaged tissues. Owing to the potential of magnetic nanoparticles to trace, spatially organize, and stimulate stem cells, such versatile nanoparticles portend a paradigm shift to tissue regeneration procedures and are tested in numerous preclinical studies. ${ }^{12-15}$

However, one major obstacle engineered nanoparticles (including the magnetic ones) still face in their therapeutic mission, concerns a decreased stability and loss of targeting potential in the complex biological environment. ${ }^{16-21}$ Indeed, despite efforts to customize nanoparticles surface, made with the ambition to deliver nanoparticles to a specific target, the most probable nanoparticles' fate is to end up within endosomes of hepatic and splenic macrophages, where nanoparticles undergo gradual "digestion". Therefore, the topical nano-bio-interface query of the current and following decade relates to processes occurring within the (intra)cellular environment, which profoundly alters the physical and chemical properties of nanoparticles. Because of the difficulty to perform qualitative and quantitative metrics on nanoparticles in situ, 
within concerned subcellular environments, this issue is still overlooked. Moreover, analyses are even harder over long periods of time. Nevertheless, the early studies evaluating nanoparticles long-term intracellular transformations unanimously lead to the premise that intracellular (endosomal) environment transforms nanoparticles identity. ${ }^{19,}$ 21-26

Finally, while nanotechnology emerged rather recently, magnetic nanoparticles could be traced as far back as Archean, ${ }^{27}$ when magnetic particles allowed organisms magnetotaxis along the geomagnetic field. ${ }^{28}$ And surprisingly, bacterial cells ${ }^{29}$ are not the only ones capable of magnetic bio-mineralization. Magnetite nanoparticles were also found in humans, ${ }^{30-32}$ but their origin (environmental versus biosynthesized) is still subject to discussions. ${ }^{33,}{ }^{34}$ We just demonstrated that magnetic nanoparticles are no stranger to mammalian cells, as pristine human mesenchymal stem cells (MSCs) can also generate magnetic nanoparticles anew, from non-magnetic precursors. ${ }^{2,3}$

In this Account, we focus on magnetic nanoparticles, which have an unrivaled advantage for therapy, diagnosis, and tissue engineering approaches. In order to apprehend nanoparticles full potential, we first describe how the structure and functionality of nanoparticles evolve upon cellular processing. In order to provide specific answers that link nanoparticles fate to the therapeutic outcome, we describe how endosomal compartmentalization alters both nanoparticles theranostics properties and nanoparticles integrity. The latter is lost over time, when the iron sheds away from nanoparticles and integrates the endogenous mechanisms involved in iron homeostasis. This gradual breakdown of magnetic nanoparticles can be monitored and quantified, as the loss of nanoparticles integrity correlates with the loss of nanoparticles magnetic properties. Yet, strikingly, the loss of magnetic properties is, in some cases, only transient. Within the cells, an intriguing phenomenon can occur, where exogenous nanoparticles completely degrade, to endogenously reform anew.

\section{THE FIRST STEPS OF NANOPARTICLES INTRACELLULAR JOURNEY: INTERNALIZATION AND STORAGE IN ENDOSOMES.}

Many magnetic nanoparticle synthesis methods were developed for prospective medical applications, each chemical approach providing different levels of control over nanoparticles shape, size, composition, and biocompatibility. The most conventional, easy, and inexpensive synthesis method is the co-precipitation, ${ }^{35}$ which allows obtaining aqueous dispersions of iron oxide nanoparticles. The high temperature thermal decomposition process using surfactants leads to an excellent control over particle size and monodispersity. ${ }^{36,37}$ The resulting nanoparticles are hydrophobic and a post-functionalization is necessary for water transfer. Aqueous sol-gel methods are used as well, but require the use of heat treatments to obtain 
high crystallinity. The polyol sol-gel process however takes advantage of higher boiling points to avoid further heat treatments. ${ }^{38}$ The resulting nanoparticles have intermediate size distribution in between co-precipitation and hydrothermal routes and can be directly dispersed in water due to the presence of polyols at nanoparticles surface. Finally, non-aqueous sol gel approach, such as the benzyl alcohol route, ${ }^{39}$ also provides high crystallinity, purity, and reproducibility, without the need of surfactants or heat treatment. Subsequently, the extraction from benzyl alcohol is required to obtain water dispersion. All these chemical synthesis approaches provide a magnetic core, and they all result in the covering of the core by a chosen coating. The latter governs nanoparticles stability in aqueous dispersions and also influences nanoparticles interactions with cells. However, as soon as the nanoparticles are placed in biological environments, such as in cell cultures or inside the body, their surface is readily changed by adsorption of adjacent ions and proteins.

The nanoparticles and protein complexes are then systematically internalized by cells via endocytosis (Figure 1a) and stored within the endosomes (Figure 1b-e). At a given incubation time, nanoparticles concentration, and nanoparticles features (e.g. coating, shape and size) will result in varying quantities of nanoparticles per cell. Magnetic nanoparticles taken up by cells can be quantified by the determination of total iron mass or by magnetometry and magnetophoretic approaches. The latter correlates the magnetization of the cells to the amount of intact nanoparticles. To totally discriminate endogenous iron from nanoparticles-provided exogenous iron, iron isotopes with low natural abundance can be used as building blocks for nanoparticles. ${ }^{40,41}$ Coating can drive differential capture rates, particularly in vitro, mainly due to the variation of the nanoparticle charge and the aggregation status, ${ }^{42}$ and nanoparticle size can control cellular responses. ${ }^{43}$ The internalization of magnetic nanoparticles can also be enhanced by the application of a remote magnet. ${ }^{44,45}$ Importantly, the cell-loading procedure has to be tightly monitored, as not only the nanoparticles concentration, but also the decrease of nanoparticles suspension stability (e.g. aggregate formation) may lead to increased cell toxicity. 27,46

\section{ENDOSOMAL CONFINEMENT IMPACTS THERAPEUTIC AND IMAGING FUNCTIONS.}

Cellular internalization of magnetic nanoparticles modifies their therapeutic functions. For magnetic hyperthermia (Figure 1g), heating was evaluated for nanoparticles in water or in cells (Figure $1 \mathrm{f})^{47}$. Regardless of the type of nanoparticles we tested, it appeared that cellular internalization decreased the heating efficiency. Nevertheless, two different behaviors were evidenced. When the magnetic core is superparamagnetic and the magnetic relaxation is governed by Néel mechanism, the decrease in heat generation (about 2-fold) upon cellular 
internalization is not very pronounced. By contrast, when the magnetic core is ferromagnetic, the relaxation is governed by Brownian motion. As the latter is inhibited by the strong intracellular confinement of the nanoparticles in the endosomes, the heating is dramatically affected (> 10-fold decrease in generated heat). This finding recently led to chemical strategies to enable nanoparticle motion in endosomes and restore intracellular magnetic hyperthermia efficiency. ${ }^{48}$ Worthy of note, we just mention here that confinement may affect other nanomedicine modalities, such as laser-mediated photothermia. The latter mostly relies on the use of plasmonic gold nanoparticles, and an opposite effect could be observed, with an increased heat generation in the intracellular environment. ${ }^{49,50}$ In a similar way, the intracellular confinement of magnetic nanoparticles, which are T2-agents (negative contrast agents) due to their high $r 2$ values (transverse relaxivity), is beneficial for magnetic resonance imaging (MRI). When confined in cells, the magnetic nanoparticles $\mathrm{r} 1$ value (longitudinal relaxivity) decreases massively (100-fold or more), while $\mathrm{r} 2$ only falls by a factor of 2.5 , resulting in a remarkable increase in the $\mathrm{r} 2 / \mathrm{r} 1$ ratio (almost 10 -fold), governing the $\mathrm{MRI}$ negative contrast (Figure 1h). ${ }^{51}$ Single cells can thus be tracked by MRI, ${ }^{52}$ such as lymphocytes (Figure 1i), labeled with magnetic nanoparticles, which could be detected and distinguished while infiltrating a tumor. ${ }^{53}$ Cells loaded with magnetic nanoparticles can also be guided using external magnets. In this case, the cells magnetization is directly proportional to the amount of intact nanoparticles, and is therefore not impacted by the endosomal confinement. We have previously described the feasibility of magnetic guiding and showed that nanoparticle-loaded cells preferentially migrate to the limb on which an external magnet was placed. ${ }^{54}$ 


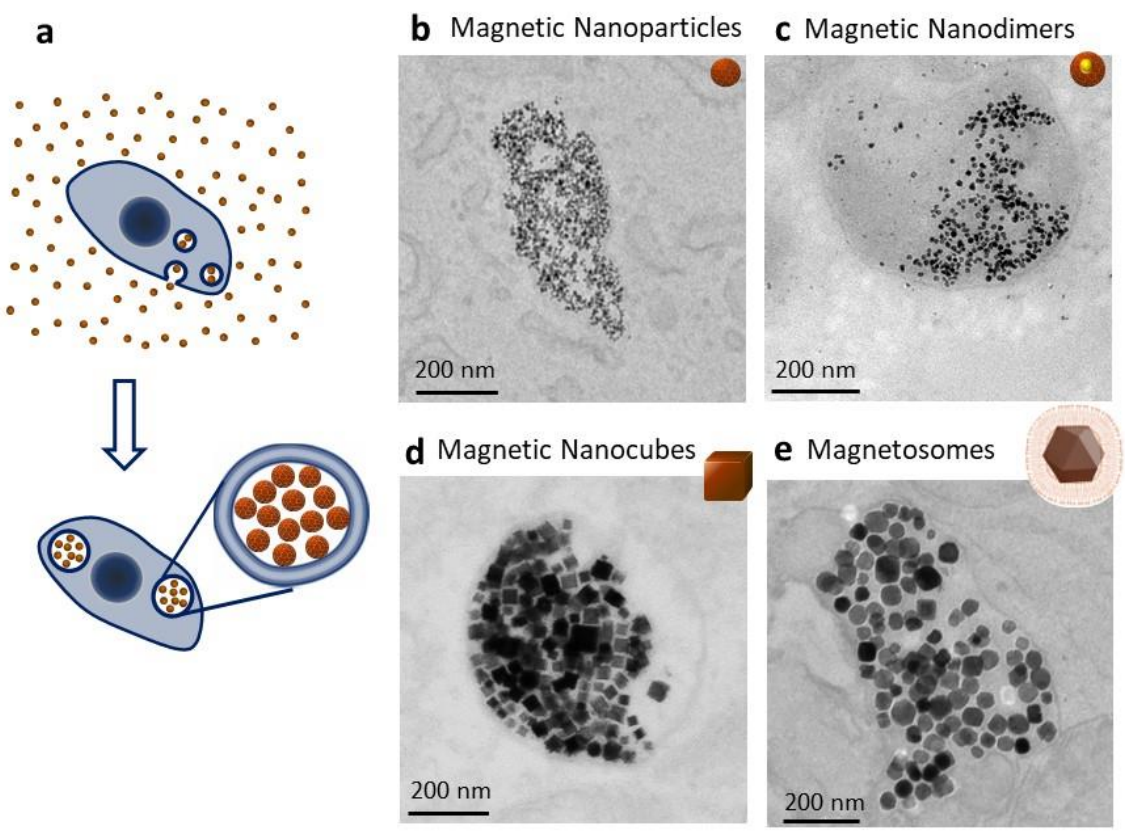

f

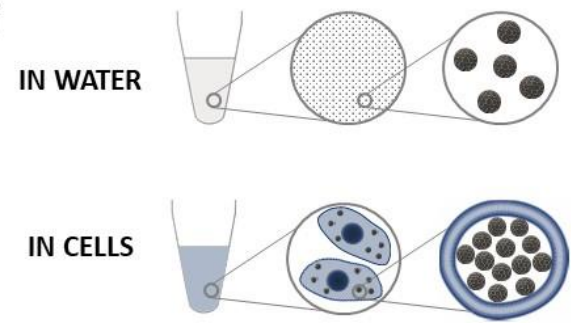

g Magnetic hyperthermia

- Mag Nanoparticles
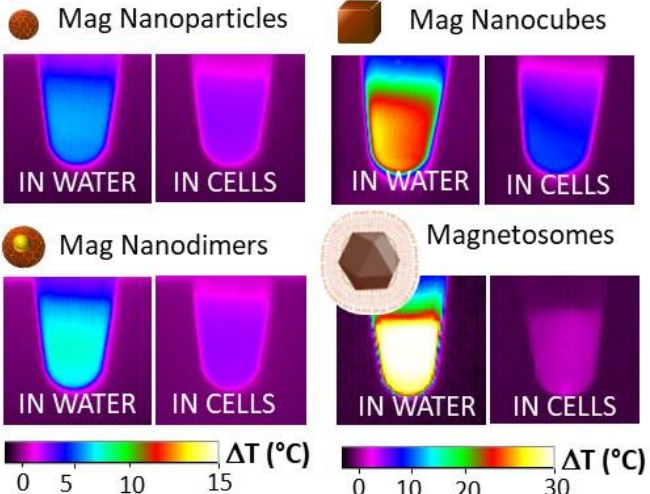

\begin{tabular}{c} 
h Magnetic resonance \\
100 \\
$80 \quad-O-$ IN WATER \\
\hline- IN CELLS
\end{tabular}
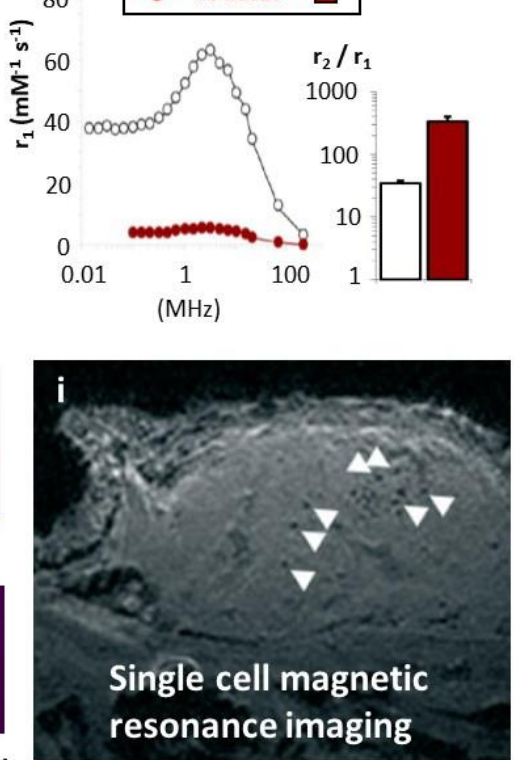

Figure 1: Endosomal internalization of magnetic nanoparticles and effect of intracellular confinement on hyperthermia and imaging applicability. (a) Nanoparticles are internalized within cellular endosomes by a simple incubation procedure, where cultured cells are coexposed to nanoparticles. (b-e) Nanoparticles confinement in cells' endosomes shown by transmission electron microscopy (TEM); (b) magnetic nanoparticles obtained by coprecipitation, (c) Iron (magnetic)/gold nanodimers and (d) magnetic nanocubes, both obtained by thermal decomposition, (e) biological magnetosomes extracted from magnetotactic bacteria. Data from refs ${ }^{1-3,55}$. (f-g) Effect of intracellular confinement on magnetic hyperthermia potential assessed by calorimetry. The heating efficiency of nanoparticles compared in water and in cells (f), after exposure to magnetic hyperthermia $(\mathrm{g})$ 
for iron oxide nanoparticles. Data from ref ${ }^{47}$. (h) Intracellular confinement of the magnetic nanoparticles impacts their relaxivity, remarkably increasing their $\mathrm{r} 2 / \mathrm{r} 1 \mathrm{ratio}$, favorable for their use as T2 contrast agents for MRI. Data from ref ${ }^{51}$. (i) MRI detection of individual lymphocytes (white arrows) labeled with magnetic nanoparticles in vivo, in a murine tumor, detected $48 \mathrm{~h}$ after intravenous injection. Data from ref ${ }^{53}$.

\section{INTRACELLULAR MAGNETIC NANOPARTICLES USE IN TISSUE ENGINEERING}

The recent use of magnetic nanoparticles for tissue engineering, as for instance to enhance stem cells differentiation, largely motivates the study of their long-term fate within these stem cells, whose ultimate vocation is to repair permanently damaged tissue. For these bioengineering applications, the magnetic nanoparticle-loaded cells become magnetoresponsive and can be manipulated at distance using magnetic forces (Figure 2a), a powerful tool for functional tissue engineering. Magnetic forces were for instance used to compact cells and create macro-scale cellular assemblies, without the use of scaffolds (Figure $2 \mathrm{~b}-\mathrm{c}$ ). The tissues formed can be magneto-mechanically stimulated at a distance using either static or dynamic magnetic fields applied via permanent magnets ${ }^{56}$ or electromagnets, ${ }^{4}$ respectively (Figure 2d). Magnetic stimuli were used to orient the differentiation of stem cells toward specific tissue types, ${ }^{57}$ showing for instance that a cyclic magnetic stretching of embryonic stem cells largely increases the generation of cardiomyocytes. ${ }^{4,56}$ The magnetic arrangement of cells has also been exploited for the development of various tissue structures such as cell spheroids, sheets, or rings (Figure 2e-g). ${ }^{57-60}$ Generally, magnetically labeled cells are attracted toward the bottom of a culture dish with a magnet being placed underneath, but cell spheroids could also be formed via magnetic levitation, with cells being in suspension at the liquid-air interface (Figure 2h). ${ }^{61}$ 

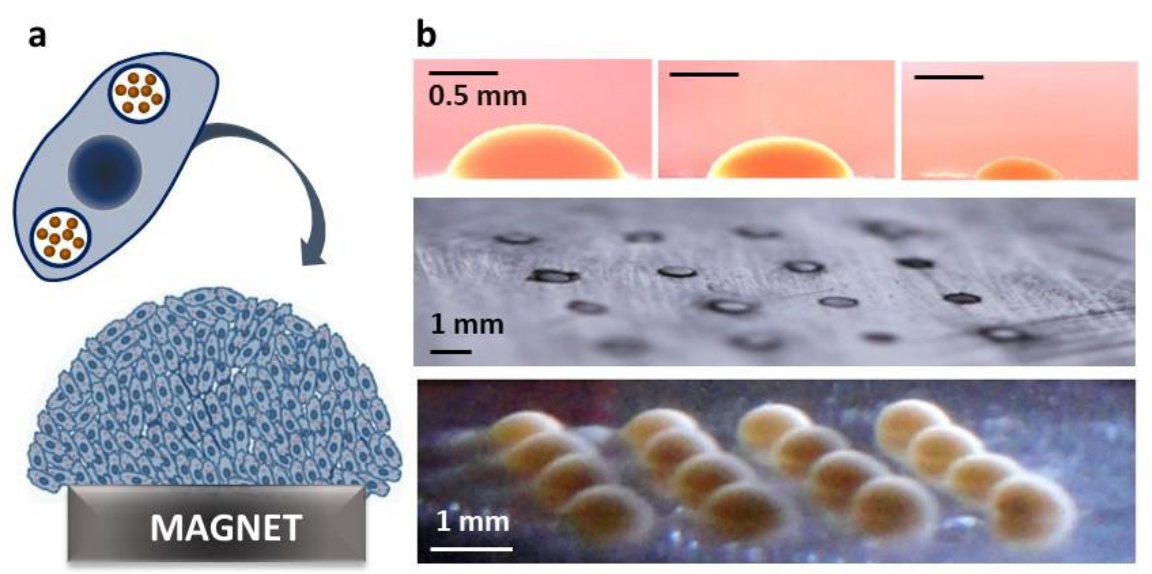

C
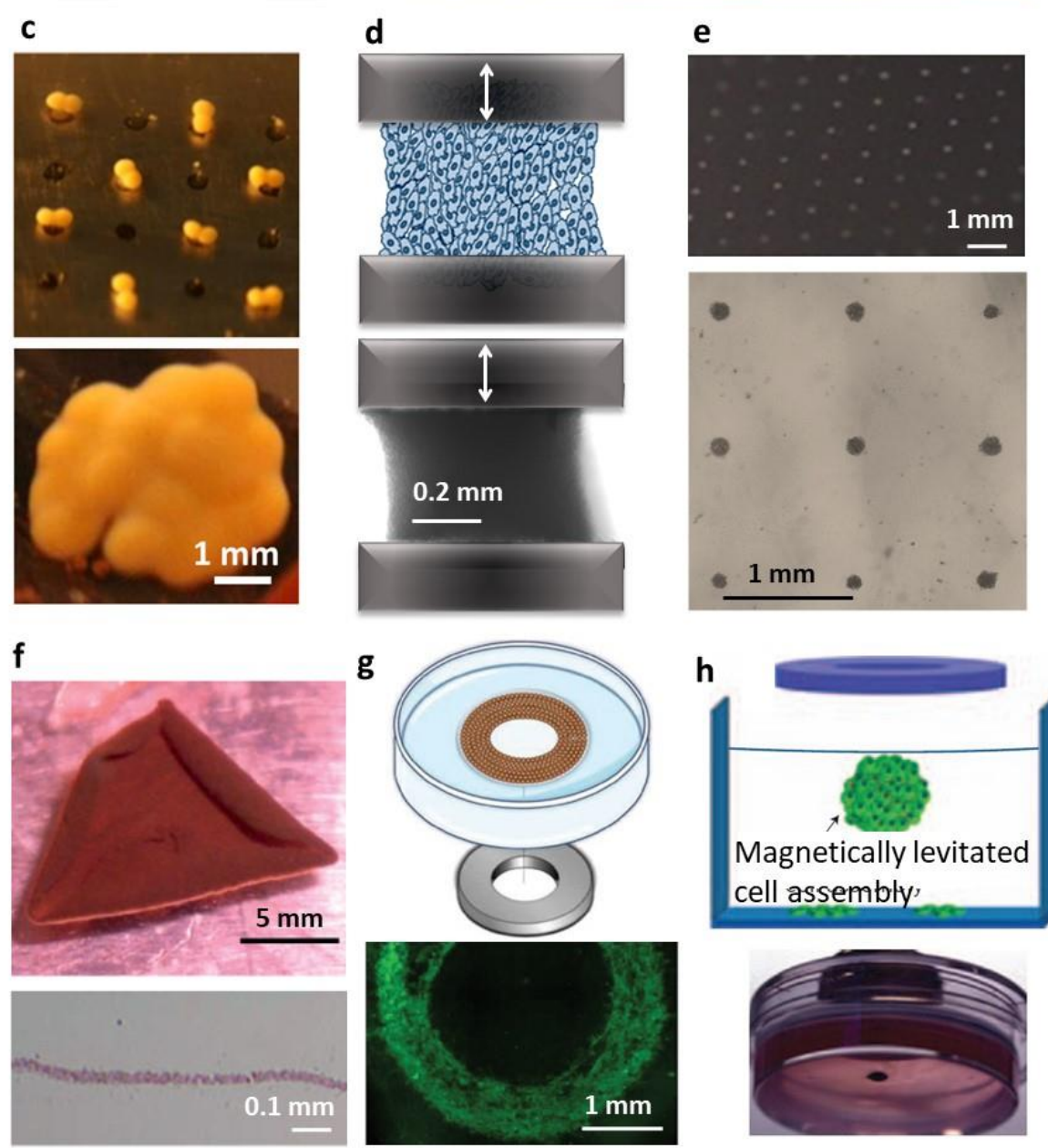

Figure 2: Magnetic tissue engineering using magnetically labeled stem cells. (a) After a simple incubation, magnetic nanoparticles are internalized within the endosomes of cells. These magnetized cells can be directed by remote magnetic forces, using permanent or electromagnets. (b) Homogenous size cell aggregates can be formed magnetically using a patterns of magnetic micro-tips. (c) Cell aggregates can be forced to fuse using remote magnetic attractors, gradually combining two-by-two, then four-by-four, etc. to form a millimeter-scale tissue, here for cartilage tissue engineering. Data from ref ${ }^{57}$ (d) Cell aggregates can also be mechanically stimulated via stretching using movable magnetic micro-tips. Data from ref ${ }^{56}(e)$ Magnetic cell patterning can be achieved on arrays, with cells immediately attracted to the surface where the magnetic micro-tips are positioned. Data from ref $^{4}(\mathrm{f}-\mathrm{g})$ Different tissue 
shapes can be achieved such as cell-sheets $(\mathrm{f})$, or rings $(\mathrm{g})$, reproduced with permission from refs ${ }^{58}$ and ${ }^{59}$, respectively, copyright 2007 and 2020 John Wiley \& Sons. (h) Cell assembly formed after magnetic levitation. Reproduced with permission from ref ${ }^{61}$, copyright 2010 Nature publishing group.

\section{CAN MAGNETIC NANOPARTICLES DEGRADE IN VIVO?}

For any use of magnetic nanoparticles for therapeutic or diagnostic purpose, the main issue and challenge is to determine nanoparticles long-term fate after achieving their therapeutic mission. The initial steps towards the understanding of magnetic nanoparticles fate in the biological environment have been to study their transformation in vivo, in rodents. For this, magnetic nanoparticles were injected intravenously, and the location and repartition of iron were observed in organs, by distinguishing the magnetic from the non-magnetic form. ${ }^{17,62-64}$ Magnetism measurements were performed together with histological and TEM imaging, showing the course of nanoparticles degradation within diverse organs. Most of magnetic nanoparticles were found within the liver and the spleen. Inside these organs, the nanoparticles were located intracellularly, within endosomes. The latter gradually fuse with lysosomes, and an acid-induced degradation of the nanoparticles takes place. ${ }^{17}$ In order to demonstrate how exogenous iron integrated endogenous iron metabolism and reuse pathways, iron isotopes (e.g. ${ }^{59} \mathrm{Fe}$ or ${ }^{57} \mathrm{Fe}$ ) containing nanoparticles were used. Nanoparticle-constituting iron could thus be differentiated from endogenous iron $\left({ }^{56} \mathrm{Fe}\right)$, with the isotopes being incorporated within hemoglobin. ${ }^{40,41}$ These in vivo experiments brought a general understanding of iron oxide nanoparticles fate within the organism, and more importantly evidenced that magnetic nanoparticles degrade. This generated nanosafety interrogations, ${ }^{65}$ as released iron ions could lead to metal toxicity ${ }^{66}$ as well as Fenton-derived cytotoxicity, which we will discuss further in sections 7 and 8 of this Account.

\section{CAN BIODEGRADATION BE QUANTIFIED IN CELLULO?}

For regenerative medicine applications involving the labeling of stem cells with magnetic nanoparticles, assessments at the entire organism level were insufficient to conclude on the intracellular fate of the magnetic nanoparticles, defining the need for in vitro "close-circuit" analyses allowing precise quantifications.

The monitoring of nanoparticles fate in vitro, inside living cells, and on the long term, is not simple, due to constitutive cell division and cell death. Chemical models were thus developed, consisting of media mimicking the acidic environment of lysosomes. ${ }^{67}$ TEM imaging was subsequently used to visualize in situ the gradual morphological alterations on edges and 
vertexes of magnetic nanocubes, which could be correlated to degradation. ${ }^{68}$ More recently, an in vitro tissue-mimicking model, made of human stem cells, was developed to quantitatively assess bio-transformations in the quiescent biological environment. ${ }^{55}$ This model consists in gathering stem cells by centrifugation, after which the cells form a cohesive 3D spheroid that can remain viable for months (Figure 3a). The stem cell-spheroids mature as tissues and produce a self-secreted extracellular matrix. As cell division stops, nanoparticle dilution is avoided. In such models, TEM imaging revealed a loss of structural integrity of internalized nanoparticles (Figure 3b-e). Furthermore, the intracellular biodegradation of iron oxide nanoparticles was quantitatively monitored using magnetometry measurements (Figure $3 f-g$ ). The cellular magnetism reflected nanoparticles integrity, and a decrease in magnetism indicated nanoparticles degradation. Analyses were made with magnetic nanoparticles produced by different synthesis protocols: co-precipitation (rock-like spherical nanoparticles), ${ }^{2}$, ${ }^{55}$ benzyl alcohol synthesis route (nanospheres), ${ }^{1,42}$ high temperature polyol synthesis (flowerlike multicores) ${ }^{69}$ thermal decomposition (nanocubes or iron oxide gold dimers), ${ }^{55}$ or bacterial synthesis (biogenic magnetosomes). ${ }^{3}$ Altogether, the results obtained in the stem cell-spheroid model confirmed a progressive decrease in magnetism, indicating a degradation of all nanoparticles. The latter was almost complete one month following nanoparticles exposure, for low doses of internalized nanoparticles per cell (in the $1 \mathrm{pg}$ of iron per cell range), without impacting cell differentiation. Besides, the degradation kinetics could be correlated to nanoparticles intracellular content (slower degradation at a higher dose) ${ }^{42}$ and to nanoparticle coating (a polymer coating, $\mathrm{PAA}^{42}$ or molecular imprinted polymer (MIP) $)^{70}$, where polymers resulted in a slower degradation of nanoparticles in comparison to citrate coated ones). Importantly, for all tested iron oxide nanoparticles, nanomagnetism brings substantial advantage to quantitatively track nano-transformations within cells.

For these standard magnetometer analyses, cells and tissues have to be fixed to be processed. By contrast, a bench-sized device was recently tested for longitudinal real-time monitoring of the degradation of nanoparticles within the same living cells, over several days, without affecting either cellular viability or tissue formation (Figure $3 \mathrm{~g}$ ). ${ }^{1}$ This approach confirmed a progressive degradation of the nanoparticles over time and delineated small fluctuations in the degradation process, probably linked to biological events. 


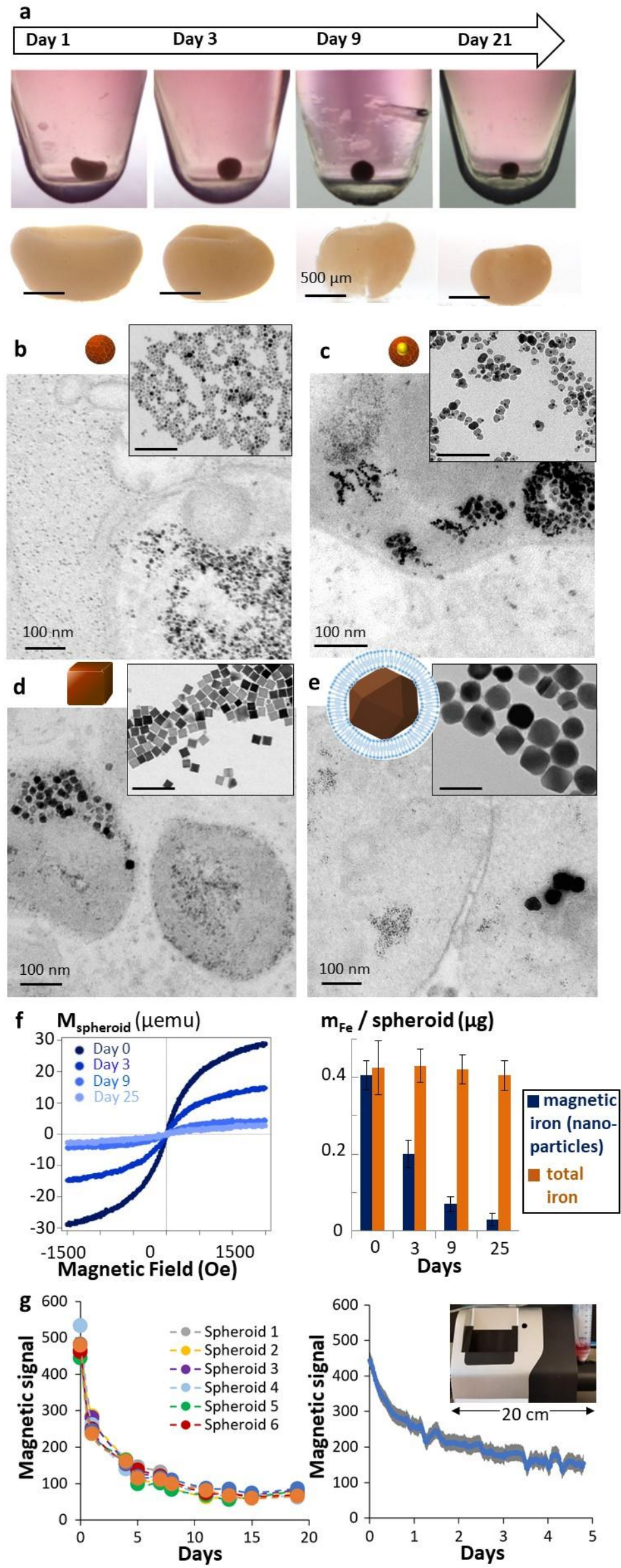


Figure 3. Biodegradation of magnetic nanoparticles over time evidenced in a 3D stem cellspheroid model via magnetic measurements. (a) Upon centrifugation, stem cells are cultured in 3D, forming a cohesive structure. Data from ref ${ }^{55}$ The spheroids remain viable along extensive culture periods allowing long-term monitoring of nanoparticles biotransformations. (b-e) TEM images of intact nanoparticles in suspension (framed panel) and same nanoparticles, internalized and metabolized by cells, visualized after 21 to 25 days of culture within the tissue model. Nanoparticles biodegradation in cellulo is demonstrated for a panel of nanostructures: (b) iron oxide nanospheres, (c) gold/iron oxide nanodimers, (d) iron oxide nanocubes, (e) magnetosomes. Data from refs ${ }^{2,3,42,55}$. (f) The magnetic moment of the spheroids is obtained via vibrating sample magnetometry (VSM) over time. Results evidence a progressive decrease in magnetic iron while total iron remains constant (right panel), demonstrating a progressive degradation of the magnetic nanoparticles in the tissue model over time. Data from refs ${ }^{2,55}(\mathrm{~g})$ Magnetometry measurements on the tissue model, in realtime, while keeping the cells viable were also achieved using a small bench-top magnetic sensor device. Data from ref ${ }^{1}$. Measurements were either obtained punctually (left panel) or continuously on a same spheroid (right panel).

\section{IRON METABOLISM AS AN ESSENTIAL STEP IN NANOPARTICLES DEGRADATION PROCESSES}

Iron is essential in many biological functions. ${ }^{71}$ The natural human iron metabolism confers a particular advantage to magnetic nanoparticles in nanomedicine, as their iron oxide core might be bio-assimilated. However, the iron redox properties, which are intimately associated to its activity with proteins, also imply a potential Fenton-derived toxicity. To minimize toxicity, specific protein systems operate within the body and 'chaperone' the metal, allowing its uptake, transport, storage, and reuse.

Upon nanoparticles internalization and concentration within endosomes, others ${ }^{72-76}$ and us $^{1-3 \text {, }}$ $42,55,70$ not only observed the specific synthetic nanoparticles, but also distinct, more or less electron-dense structures, with sizes ranging from 5 to $7 \mathrm{~nm}$. The number of these structures, which were identified as ferritin proteins, increased over time, as the number of endosomal nanoparticles was decreasing. These structures were present both inside the endosomes and inside the cytosol. The role of the ferritin proteins is to intercept the iron ions that are released from synthetic nanoparticles, and their structure is the same, regardless of the initial shape of cell-internalized nanoparticles, as evidenced in Figure 4.

A method to address the integration of iron released over nanoparticles degradation, consists in assessing the impact of nanoparticles degradation on iron binding proteins expression by quantitative PCR. The genes related to iron metabolism include the ones associated to iron storage (ferritin/FerrH \& FerrL), transport (transferrin/TFR1; dimetal transporters/DMT1), and export (ferroportin /SLC40A1). Ionic species released upon the degradation of chemically 
synthesized iron oxide nanoparticles (Figure 4a, 4b, 4d), ${ }^{2,55}$ or magnetosomes made by magnetotactic bacteria (Figure $4 \mathrm{e}$ ), ${ }^{3}$ can all be stored within the ferritin protein core. As a consequence, the degradation systematically correlates with an up-regulation of ferritin genes expression (Figure 4c, 4f). 2, 3, 69 A homeostatic balance in gene expression of transport and export proteins is also generally observed, with a decreased expression of TFR1, to limit iron uptake by cells, and increased ferroportin, allowing the export of iron excess.

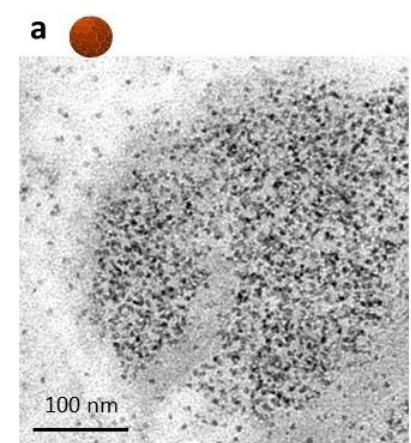

b

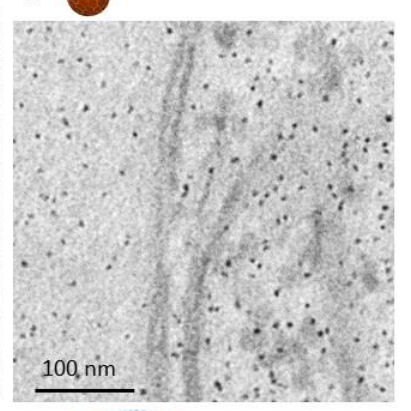

c
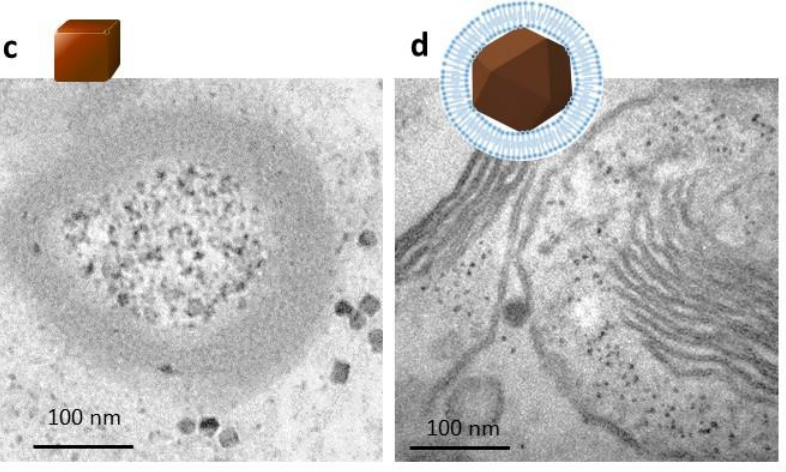

e
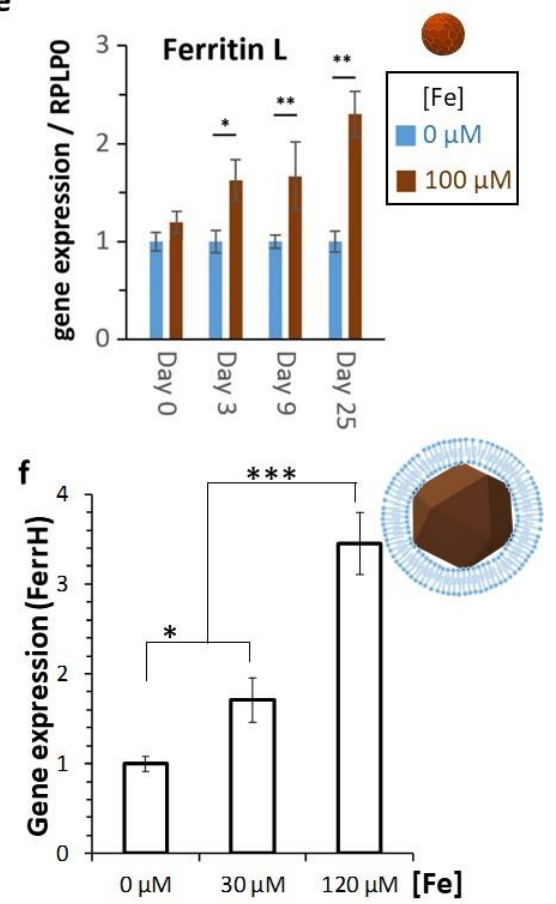

Figure 4: Storage of iron in ferritin proteins, upon ionic release following nanoparticles degradation. TEM micrographs of (a) rock-like nanoparticles made by coprecipitation, (b) spherical nanoparticles made by benzyl alcohol synthesis, (c) nanocubes made by thermal decomposition, and (d) magnetosomes made by bacterial synthesis, internalized in stem cells and cultured in cellular spheroids for 21-25 days, showing little if any intact nanoparticles and evidencing the approximatively 6 -nm electron-dense dots within the endosomes and within the cytoplasm of cells. These dots correspond to the ferritin protein, loaded with iron. Increased gene expression of the L-subunit of ferritin for cells labeled with rock-like nanoparticles (e) and the $\mathrm{H}$-subunit of ferritin for cells labeled with magnetosomes (f) at days 21-25 supports the transfer of the released iron into the protein cage. Data from refs ${ }^{3,55}$.

\section{WHAT HAPPENS NEXT? RECRYSTALLIZATION OF BIOGENIC MAGNETIC NANOPARTICLES}

It is now obvious that in the cellular environment, magnetic nanoparticles evolve over time and start rapidly degrading. As magnetic nanoparticles mainly consist of an iron oxide core, the metal (iron) ions stemming from degraded nanoparticles subsequently integrate the 
physiological iron metabolism pathway and transition into iron depots, the ferritins. Within ferritin proteins, the iron is stored in the non-magnetic ferrihydrite form.

Phenomenally, we just demonstrated that under specific conditions, stem cells can also exploit ionic species of iron, released during the process of degradation of nanoparticles made by coprecipitation $^{2}$ or biological magnetosomes ${ }^{3}$. The ionic species were then used to resynthesize novel, biogenic, magnetic nanoparticles (Figure 5). These de novo synthesized nanoparticles a priori exhibit a magnetite structure. In our experiment, the internalized magnetic nanoparticles were first degraded (within the first 3 days), this degradation correlated with a decrease in cellular magnetization. Subsequently, the cells almost completely remagnetized, reflecting the re-synthesis of magnetic nanoparticles (Figure 5a-d). These recrystallized magnetic nanoparticles made by human stem cells are around $8 \mathrm{~nm}$ in size (Figure $5 e-h)$.

The neo-synthesis of biogenic nanoparticles most probably involves the ferritin protein, which commonly stores the iron in its non-magnetic ferrihydrite form, but can also contain magnetic iron phases such as magnetite or maghemite. ${ }^{77}$ While the biomineralization within the ferritin cage naturally occurs in bacteria, the production of magnetoferritin ${ }^{78}$ from the apoferritin protein has been mostly reported in reconstituted in vitro suspension. Nevertheless, the presence of magnetism sometimes observed in mammals has recently been attributed to iron-rich ferritins. ${ }^{74}$ Interestingly, the nanoparticles neo-synthetized by human stem cells described above $^{2,3}$ have the size of the cavity of the ferritin protein, potentially indicating that magnetoferritin could be formed in human cells in case of iron excess. However, detailed processes of this biomineralization in mammalian cells have yet to be unraveled.

Importantly, the biosynthesis of magnetic nanoparticles correlated with no cellular toxicity. This innocuousness of in cellulo-synthesized nanoparticles was observed even at high doses of intracellular iron (over $10 \mathrm{pg}$ per cell). On the contrary, when biosynthesis did not occur, cellular toxicity was detected at these doses. This indicates that biosynthesis might act as a potential protective mechanism. 

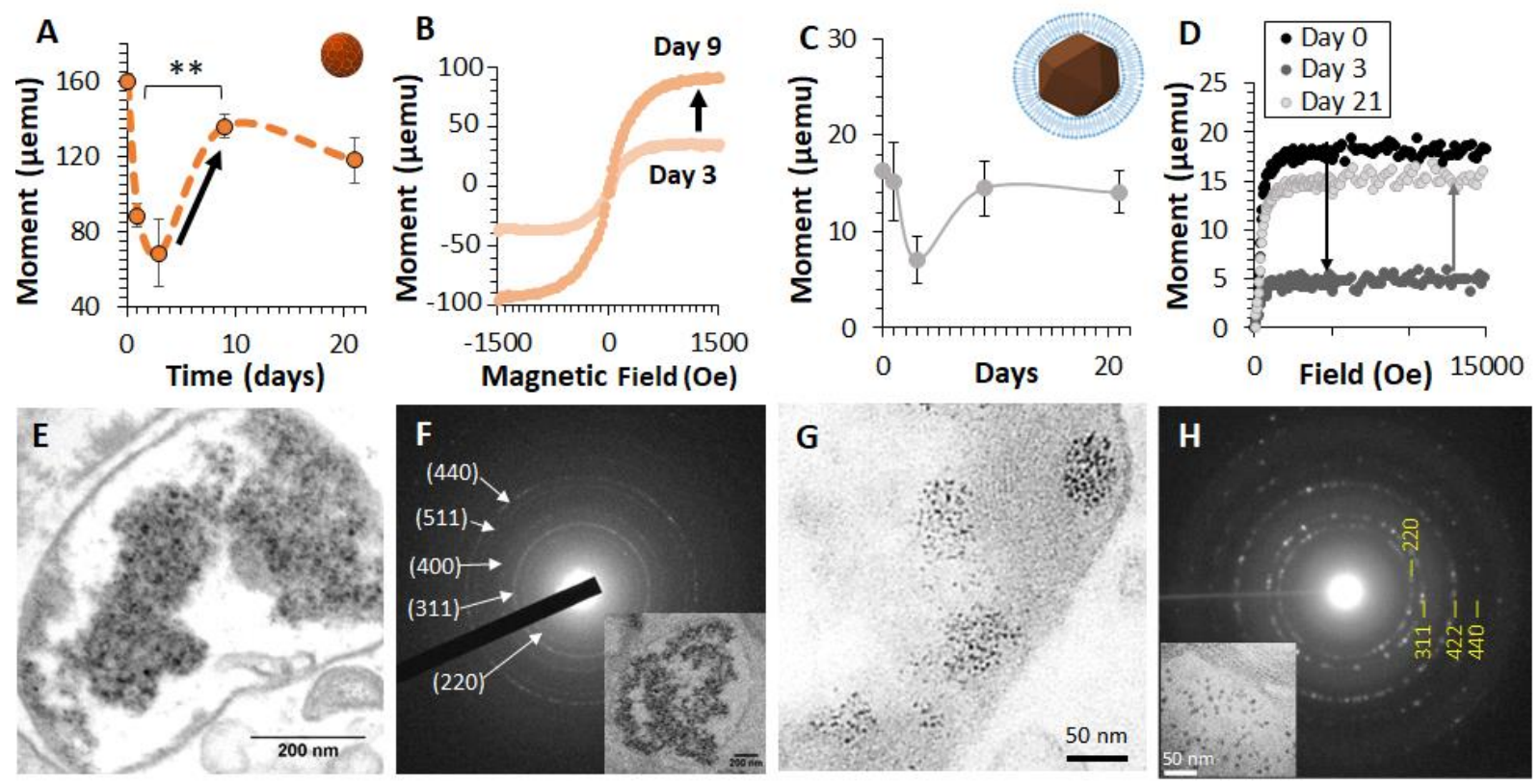

Figure 5: Biomineralization of magnetic nanoparticles anew by human cells following degradation of synthetic (8-nm made by co-precipitation) or biogenic (magnetosomes made by bacteria) nanoparticles. Data from refs ${ }^{2,3}$. (a-d) Magnetometry assessment of the recrystallisation process. After internalization in human stem cells of the nanoparticles (a-b) or the magnetosomes (c-d), the cells magnetism $(a, c)$ evidences an important decrease from day 0 to 3 (degradation) followed by a clear increase back between day 3 and 9 , indicating the synthesis of magnetic nanoparticles anew produced by the cells themselves. The magnetization curves obtained at day 3 and day $9(b, d)$ clearly demonstrate the emergence of a magnetic cellular signal. (e-h) Electron microscopy imaging and analysis of the biosynthesized nanoparticles. TEM images show the biosynthesized magnetic nanoparticles ( $8 \mathrm{~nm}$ in diameter) located in the endosomes of the cells at day 21 for both the synthetic nanoparticles (e) and for the magnetosomes (g). Selected Area Electron Diffraction (SAED) pattern of endosomes filled with biosynthesized nanoparticles (targeted endosome is shown in the boxed images) display diffraction rings that can be indexed to lattice planes of magnetite, again for both nanoparticles (f) and magnetosomes (h).

\section{MAGNETISM IN HUMANS}

The biosynthesis of magnetic nanocrystals in microorganisms is vastly documented and exploited; yet, the studies describing the genesis of magnetic crystalline materials in mammalian cells are rather scarce. To the best of our knowledge, the studies described above were the first to report the possibility for an in situ synthesis of magnetic crystals in human cells (precisely, mesenchymal stem cells MSCs). ${ }^{2}{ }^{3}$ Nevertheless, the existence of magnetic crystals in human brain samples was evidenced almost three decades ago. ${ }^{30}$ The spatial distribution of magnetite was studied on dissected whole human brains and showed that magnetite is preferentially partitioned in the cerebellum and brain stem. ${ }^{79}$ Individuals (healthy subjects and patients suffering from neurodegenerative diseases) were monitored by magnetic 
resonance imaging (MRI) or underwent magnetoencephalography, which allowed tracking and quantifying magnetite (Figure 6a-b). ${ }^{80}$ These analyses revealed the presence of magnetite in both populations, but larger amounts were detected in the brain of aging male subjects and in patients suffering from neurodegenerative diseases such as Alzheimer. There is now general consensus that Alzheimer disease is associated with a strong deregulation of the iron metabolism, leading to iron excess. ${ }^{81}$ It could be thus hypothesized that magnetic nanoparticles form due to iron overload and minimize oxidative stress, which would be otherwise massively engendered by iron ions.

After the pioneering works on the brain, magnetic crystals were also found in other human tissues, such as the heart, spleen, liver, ethmoid bone, cervical skin, and tumors. ${ }^{30-32,82-84}$ The source of magnetic crystals has not been clearly ascertained. A large body of literature suggests an exogenous origin of magnetic crystals. Exogenous sources mainly include atmospheric pollution (particularly diesel exhaust and particulates derived from brake abrasion). ${ }^{34}$ Airborne magnetite can thus penetrate the brain, probably via the olfactory nerve (Figure 6c). However, some previous studies also suggested a potential formation of magnetic crystals within the human body. This assumption was only recently empirically evidenced in vitro in human MSC, either transfected with the magnetotactic bacterial gene mms6, ${ }^{85}$ or by us in pristine human MSC after exposure to synthetic nanoparticles. ${ }^{2}{ }^{3}$ Interestingly, it has been indicated that exogenous magnetic nanocrystals can be distinguished from endogenous ones by their shape and their crystal structure. ${ }^{33}$

Magnetite crystals might also be the most plausible cause allowing some humans to transduce the changes in magnetic fields strength into an active neural response. This conclusion was drawn after exposing subjects to very weak magnetic fields $(35 \mu \mathrm{T})$ oriented along different directions, while monitoring the electrical activity of participant's brains by electroencephalography (EEG) (Figure 6d-f). ${ }^{86}$ When the magnetic field was shifted, the participants did not experience any obvious feelings. However, in some participants, the EEG revealed a drop in amplitude of their EEG alpha waves. Such responses typically occur when persons detect and process a sensory stimulus and could reflect some kind of individual differences in navigational ability. The importance of weak magnetic fields was also emphasized in orientation studies conducted on animals. ${ }^{87}$ Migratory birds can for instance filter magnetic signals and only respond to those that were environmentally relevant. 

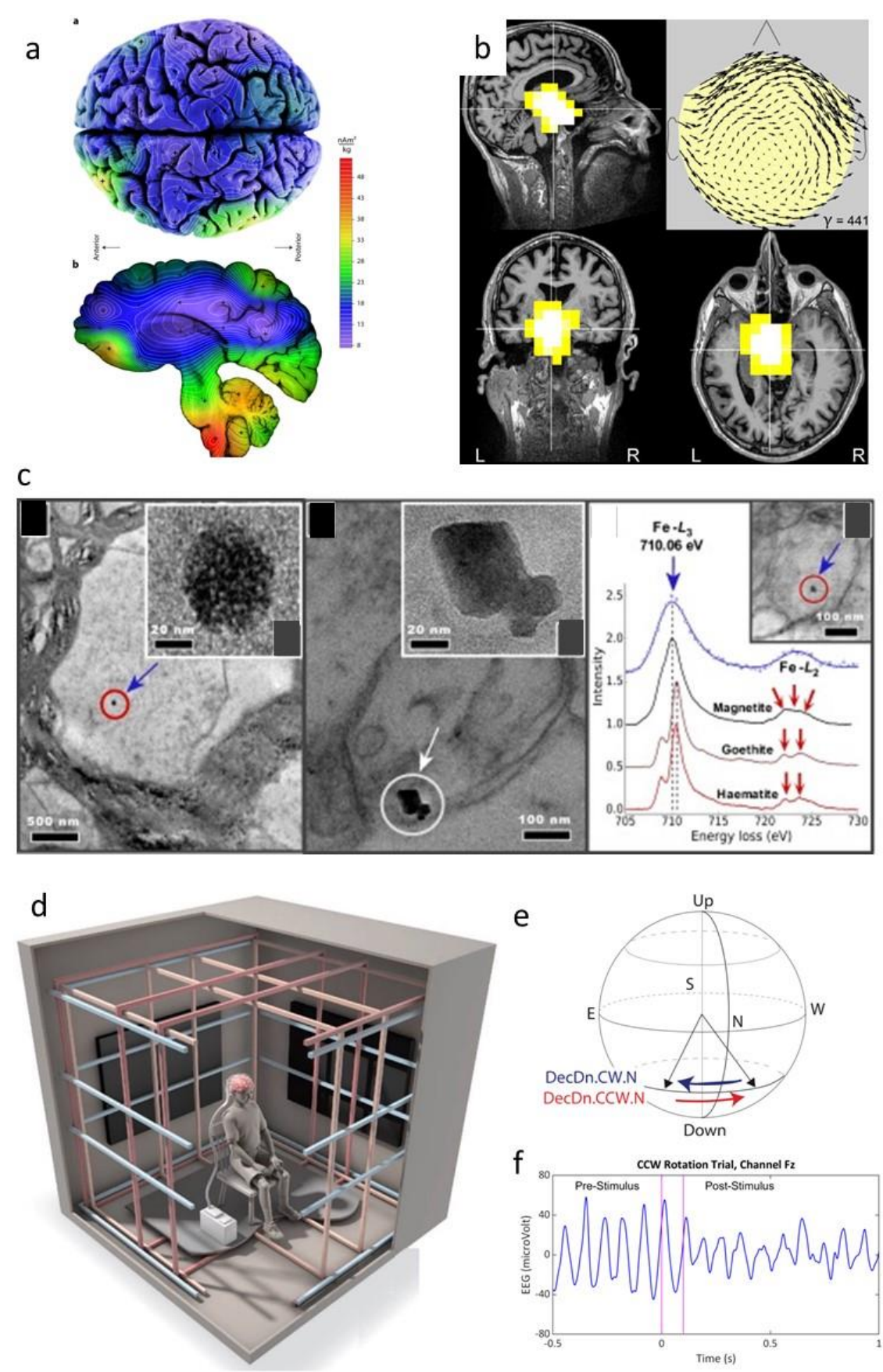

Figure 6: Magnetic nanocrystals in the human brain. (a) Higher magnetization intensities are detected post-mortem in the brain stem and cerebellum than the cerebral cortex. Reproduced with permission from ref $^{79}$, copyright 2018 Nature publishing group. (b) Magnetoencephalogram of the brain of healthy human subjects indicates source localization and mass. Reproduced with permission from ref ${ }^{80}$, copyright 2019 John Wiley \& Sons. (c) Presence of pollution-derived magnetite nanoparticles in the human brain. Reproduced with permission from ref ${ }^{33}$, copyright 2016 National Academy of Sciences. (d-f) Geomagnetic sensing in humans. Reproduced with permission from ref ${ }^{86}$, copyright 2019 Society for Neuroscience. (d) Schematic drawing of the Faraday cage was specifically designed for the testing of human magnetoreception. (e) Schematic showing the magnetic field rotations used in the experiment. The participant sits facing North, while the downwards-pointing field rotates CW (blue arrow) from Northwest to Northeast or CCW (red arrow) from Northeast to Northwest. (f) EEG from a single channel $(\mathrm{Fz})$ centered over the top of the head. Pink lines show the 100 millisecond 
CCW rotation. Large alpha waves in the pre-stimulus period get smaller following the field rotation.

\section{CONCLUSION AND PERSPECTIVES}

Magnetic nanoparticles have an undisputed potential in the medical field. However, the scientific community obviously did not gather enough data to obtain a full picture of the behavior of magnetic nanoparticles in the biological environment. And yet, such research should be performed to vulgarize theranostics applications. The overall identity of a nanoparticle is a result of the interplay of its physical, synthetic, and biological identities. For magnetic nanoparticles, the magnetic core defines their physical identity and is responsible for their multiple functionalities (imaging, heat generation, magneto-responsiveness). Conversely, nanoparticles chemical design (size, shape, surface coating) defines the synthetic identity. The interactions with biological fluids affect the surface chemistry (and alter nanoparticles synthetic identity). Subsequently, the nanoparticles sustain modifications in physiological fluids (undergo aggregation, opsonization). These modifications occur under different circumstances, in different media (within the blood or inside intracellular compartments) and at different points of time, and inflict an ever-evolving biological identity. This has been widely acknowledged, but, remarkably, the investigations rarely went beyond the surface - into nanoparticles core. In this Account, we sought to consider the evolution of magnetic nanoparticle biological identity from nanoparticles surface throughout the core. The biotransformations that occur all through the core, and inevitably occur inside the cells, directly affect nanoparticles physical identity. Thanks to the development of a stem cells-spheroid model, these transformations could be monitored over one month. During this period, the magnetism of the spheroid was systematically used as the direct signature of the nanoparticle physical identity. Biotransformations first reshape nanoparticles synthetic identity (size, shape, surface moieties/coating) and can subsequently lead to nanoparticles total degradation. When this total degradation takes place, ionic species are released, which in some cases triggers an ultimate transformation: the intracellular magnetic recrystallization, as we observed in pristine stem cells. This empirical evidence of a biogenic magnetic synthesis by human cells recalls the natural presence of magnetite crystals in humans, particularly in the brain. Studies indicate that a strong dysregulation of the iron metabolism can be associated with Alzheimer disease and leads to iron excess. This could lead to the hypothesis that magnetic biosynthesis could take place in these conditions and act as a protective mechanism to avoid oxidative stress engendered by free iron ions via the formation of magnetic iron oxides, such as magnetite, potentially in the core of the ferritin protein. Interestingly, this is also consistent with the observation that magnetic biosynthesis occurs in stem cells and enables stem cells to resist high doses of iron (delivered by synthetic nanoparticles). This iron resistance correlates with both, low toxicity and preservation of stem 
cell differentiation potential. It should also be noted that magnetic particles in humans could also be of environmental, and not of biogenic origin. However, the magnetic nanoparticles evidenced in the human brain appear to differ in shape, when compared to typical environmental nanoparticle pollutants. Nevertheless, it is possible that the fate of chemically synthesized magnetic nanoparticles and the fate of environmental nanoparticles might converge, meaning that regardless of their origin, nanoparticles might degrade and recrystallize anew. In the future, the understanding of the aspects of such intracellular bioinorganic synthesis might provide clues explaining the yet unknown origin of naturally occurring magnetic nanoparticles in humans, with a potential connection with neurodegenerative diseases. Moreover, it might open the gate to novel bioinspired synthesis methodologies in the field of bioinorganic chemistry and materials science.

\section{AUTHOR INFORMATION}

\section{Corresponding Author}

E-mail: claire.wilhelm@univ-paris-diderot.fr

\section{ORCID}

Claire Wilhelm: 0000-0001-7024-9627

\section{Author Contributions}

The manuscript was written through contributions of all authors. All authors have given approval to the final version of the manuscript.

\section{Notes}

The authors declare no competing financial interest.

\section{Biographies}

Aurore Van de Walle holds a Ph.D. in Biomedical Engineering from the University of Florida (2015). She is currently working as a post-doctoral fellow at the University of Paris.

Jelena Kolosnjaj-Tabi has a Ph.D. in pharmaceutical technology, biopharmacy and nanotoxicology from the University of Paris South (2010). She is currently a post-doctoral fellow at the Institute of Pharmacology and Structural Biology (IPBS) in Toulouse France.

Yoann Lalatonne earned his Ph.D. in 2003 from Pierre et Marie Curie University. He is currently assistant professor (MCUPH1) at the University Sorbonne Paris Nord (USPN) and the Avicenne hospital.

Claire Wilhelm has a Ph.D. in physico-chemistry from Pierre et Marie Curie University (2003). She is currently a senior research director (DR1) with the French National Center for Scientific Research (CNRS). 


\section{ACKNOWLEDGMENTS}

The authors acknowledge financial support provided by the European Research Council (consolidator grant MaTissE \#648779).

\section{REFERENCES}

1. Van de Walle, A.; Fromain, A.; Sangnier, A. P.; Curcio, A.; Lenglet, L.; Motte, L.; Lalatonne, Y.; Wilhelm, C., Real-Time in Situ Magnetic Measurement of the Intracellular Biodegradation of Iron Oxide Nanoparticles in a Stem Cell-Spheroid Tissue Model. Nano Research 2020, 13, 467-476.

2. Van de Walle, A.; Sangnier, A. P.; Abou-Hassan, A.; Curcio, A.; Hémadi, M.; Menguy, N.; Lalatonne, Y.; Luciani, N.; Wilhelm, C., Biosynthesis of Magnetic Nanoparticles from Nano-Degradation Products Revealed in Human Stem Cells. Proceedings of the National Academy of Sciences 2019, 116 (10), 4044-4053.

3. Curcio, A.; Van de Walle, A.; Serrano, A.; Preveral, S.; Péchoux, C.; Pignol, D.; Menguy, N.; Lefèvre, C. T.; Espinosa, A.; Wilhelm, C., Transformation Cycle of Magnetosomes in Human Stem Cells: From Degradation to Biosynthesis of Magnetic Nanoparticles Anew. ACS nano 2020, 14, 1406-1417.

4. Mary, G.; Van de Walle, A.; Perez, J. E.; Ukai, T.; Maekawa, T.; Luciani, N.; Wilhelm, C., HighThroughput Differentiation of Embryonic Stem Cells into Cardiomyocytes with a Microfabricated Magnetic Pattern and Cyclic Stimulation. Advanced Functional Materials 2020, 2002541.

5. Xie, J.; Liu, G.; Eden, H. S.; Ai, H.; Chen, X., Surface-Engineered Magnetic Nanoparticle Platforms for Cancer Imaging and Therapy. Accounts of chemical research 2011, 44 (10), 883-892.

6. Yoo, D.; Lee, J.-H.; Shin, T.-H.; Cheon, J., Theranostic Magnetic Nanoparticles. Accounts of chemical research 2011, 44 (10), 863-874.

7. Mai, B. T.; Fernandes, S.; Balakrishnan, P. B.; Pellegrino, T., Nanosystems Based on Magnetic Nanoparticles and Thermo-or Ph-Responsive Polymers: An Update and Future Perspectives. Accounts of chemical research 2018, 51 (5), 999-1013.

8. Zhu, L.; Zhou, Z.; Mao, H.; Yang, L., Magnetic Nanoparticles for Precision Oncology: Theranostic Magnetic Iron Oxide Nanoparticles for Image-Guided and Targeted Cancer Therapy. Nanomedicine 2017, 12 (1), 73-87.

9. Carregal-Romero, S.; Guardia, P.; Yu, X.; Hartmann, R.; Pellegrino, T.; Parak, W. J., Magnetically Triggered Release of Molecular Cargo from Iron Oxide Nanoparticle Loaded Microcapsules. Nanoscale 2015, 7 (2), 570-576.

10. Kim, J.-W.; Jeong, H.-k.; Southard, K. M.; Jun, Y.-W.; Cheon, J., Magnetic Nanotweezers for Interrogating Biological Processes in Space and Time. Accounts of chemical research 2018, 51 (4), 839849.

11. Tay, A.; Melosh, N., Nanostructured Materials for Intracellular Cargo Delivery. Accounts of chemical research 2019, 52 (9), 2462-2471.

12. Li, Z.; Hu, S.; Cheng, K., Chemical Engineering of Cell Therapy for Heart Diseases. Accounts of chemical research 2019, 52 (6), 1687-1696.

13. Cheng, K.; Shen, D.; Hensley, M. T.; Middleton, R.; Sun, B.; Liu, W.; De Couto, G.; Marbán, E., Magnetic Antibody-Linked Nanomatchmakers for Therapeutic Cell Targeting. Nature communications 2014, 5 (1), 1-9.

14. Vandergriff, A. C.; Hensley, T. M.; Henry, E. T.; Shen, D.; Anthony, S.; Zhang, J.; Cheng, K., Magnetic Targeting of Cardiosphere-Derived Stem Cells with Ferumoxytol Nanoparticles for Treating Rats with Myocardial Infarction. Biomaterials 2014, 35 (30), 8528-8539.

15. Wang, J.; Xiang, B.; Deng, J.; Lin, H.-Y.; Zheng, D.; Freed, D. H.; Arora, R. C.; Tian, G., Externally Applied Static Magnetic Field Enhances Cardiac Retention and Functional Benefit of Magnetically IronLabeled Adipose-Derived Stem Cells in Infarcted Hearts. Stem cells translational medicine 2016, 5 (10), 1380-1393. 
16. Mulens-Arias, V.; Rojas, J. M.; Barber, D. F., The Intrinsic Biological Identities of Iron Oxide Nanoparticles and Their Coatings: Unexplored Territory for Combinatorial Therapies. Nanomaterials 2020, 10 (5), 837.

17. Kolosnjaj-Tabi, J.; Lartigue, L.; Javed, Y.; Luciani, N.; Pellegrino, T.; Wilhelm, C.; Alloyeau, D.; Gazeau, F., Biotransformations of Magnetic Nanoparticles in the Body. Nano Today 2016, 11 (3), 280284.

18. Feliu, N.; Docter, D.; Heine, M.; del Pino, P.; Ashraf, S.; Kolosnjaj-Tabi, J.; Macchiarini, P.; Nielsen, P.; Alloyeau, D.; Gazeau, F., In Vivo Degeneration and the Fate of Inorganic Nanoparticles. Chemical Society Reviews 2016, 45 (9), 2440-2457.

19. Roy, S.; Liu, Z.; Sun, X.; Gharib, M.; Yan, H.; Huang, Y.; Megahed, S.; Schnabel, M.; Zhu, D.; Feliu, N., Assembly and Degradation of Inorganic Nanoparticles in Biological Environments. Bioconjugate Chemistry 2019, 30 (11), 2751-2762.

20. Soenen, S. J.; Montenegro, J.-M.; Abdelmonem, A. M.; Manshian, B. B.; Doak, S. H.; Parak, W. J.; De Smedt, S. C.; Braeckmans, K., The Effect of Nanoparticle Degradation on Poly (Methacrylic Acid)Coated Quantum Dot Toxicity: The Importance of Particle Functionality Assessment in Toxicology. Acta biomaterialia 2014, 10 (2), 732-741.

21. Soenen, S. J.; Parak, W. J.; Rejman, J.; Manshian, B., (Intra) Cellular Stability of Inorganic Nanoparticles: Effects on Cytotoxicity, Particle Functionality, and Biomedical Applications. Chemical reviews 2015, 115 (5), 2109-2135.

22. Goodman, A. M.; Cao, Y.; Urban, C.; Neumann, O.; Ayala-Orozco, C.; Knight, M. W.; Joshi, A.; Nordlander, P.; Halas, N. J., The Surprising in Vivo Instability of near-Ir-Absorbing Hollow $\mathrm{Au}-\mathrm{Ag}$ Nanoshells. ACS nano 2014, 8 (4), 3222-3231.

23. Kreyling, W. G.; Abdelmonem, A. M.; Ali, Z.; Alves, F.; Geiser, M.; Haberl, N.; Hartmann, R.; Hirn, S.; De Aberasturi, D. J.; Kantner, K.; Parak, W. J., In Vivo Integrity of Polymer-Coated Gold Nanoparticles. Nature nanotechnology 2015, 10 (7), 619.

24. Vlasova, I. I.; Kapralov, A. A.; Michael, Z. P.; Burkert, S. C.; Shurin, M. R.; Star, A.; Shvedova, A. A.; Kagan, V. E., Enzymatic Oxidative Biodegradation of Nanoparticles: Mechanisms, Significance and Applications. Toxicology and applied pharmacology 2016, 299, 58-69.

25. Ivask, A.; Scheckel, K. G.; Kapruwan, P.; Stone, V.; Yin, H.; Voelcker, N. H.; Lombi, E., Complete Transformation of Zno and Cuo Nanoparticles in Culture Medium and Lymphocyte Cells During Toxicity Testing. Nanotoxicology 2017, 11 (2), 150-156.

26. Liu, Z.; Escudero, A.; Carrillo-Carrion, C.; Chakraborty, I.; Zhu, D.; Gallego, M.; Parak, W. J.; Feliu, $\mathrm{N}$., Biodegradation of Bi-Labelled Polymer-Coated Rare-Earth Nanoparticles in Adherent Cell Cultures. Chemistry of Materials 2019.

27. Fayol, D.; Luciani, N.; Lartigue, L.; Gazeau, F.; Wilhelm, C., Managing Magnetic Nanoparticle Aggregation and Cellular Uptake: A Precondition for Efficient Stem-Cell Differentiation and Mri Tracking. Advanced healthcare materials 2013, 2 (2), 313-325.

28. Faivre, D.; Schuler, D., Magnetotactic Bacteria and Magnetosomes. Chemical reviews 2008, 108 (11), 4875-4898.

29. Kolinko, I.; Lohße, A.; Borg, S.; Raschdorf, O.; Jogler, C.; Tu, Q.; Pósfai, M.; Tompa, É; Plitzko, J. M.; Brachmann, A., Biosynthesis of Magnetic Nanostructures in a Foreign Organism by Transfer of Bacterial Magnetosome Gene Clusters. Nature nanotechnology 2014, 9 (3), 193.

30. Kirschvink, J. L.; Kobayashi-Kirschvink, A.; Woodford, B. J., Magnetite Biomineralization in the Human Brain. Proceedings of the National Academy of Sciences 1992, 89 (16), 7683-7687.

31. Brem, F.; Hirt, A. M.; Winklhofer, M.; Frei, K.; Yonekawa, Y.; Wieser, H.-G.; Dobson, J., Magnetic Iron Compounds in the Human Brain: A Comparison of Tumour and Hippocampal Tissue. Journal of The Royal Society Interface 2006, 3 (11), 833-841.

32. Sant'Ovaia, H.; Marques, G.; Santos, A.; Gomes, C.; Rocha, A., Magnetic Susceptibility and Isothermal Remanent Magnetization in Human Tissues: A Study Case. Biometals 2015, 28 (6), 951-958. 33. Maher, B. A.; Ahmed, I. A.; Karloukovski, V.; MacLaren, D. A.; Foulds, P. G.; Allsop, D.; Mann, D. M.; Torres-Jardón, R.; Calderon-Garciduenas, L., Magnetite Pollution Nanoparticles in the Human Brain. Proceedings of the National Academy of Sciences 2016, 113 (39), 10797-10801. 
34. Gieré, R., Magnetite in the Human Body: Biogenic Vs. Anthropogenic. Proceedings of the National Academy of Sciences 2016, 113 (43), 11986-11987.

35. Massart, R.; Dubois, E.; Cabuil, V.; Hasmonay, E., Preparation and Properties of Monodisperse Magnetic Fluids. Journal of Magnetism and Magnetic Materials 1995, 149 (1-2), 1-5.

36. Park, J.; An, K.; Hwang, Y.; Park, J.-G.; Noh, H.-J.; Kim, J.-Y.; Park, J.-H.; Hwang, N.-M.; Hyeon, T., Ultra-Large-Scale Syntheses of Monodisperse Nanocrystals. Nature materials 2004, 3 (12), 891-895.

37. Avugadda, S. K.; Materia, M. E.; Nigmatullin, R.; Cabrera, D.; Marotta, R.; Cabada, T. F.; Marcello, E.; Nitti, S.; Artés-Ibañez, E. J.; Basnett, P., Esterase-Cleavable 2d Assemblies of Magnetic Iron Oxide Nanocubes: Exploiting Enzymatic Polymer Disassembling to Improve Magnetic Hyperthermia Heat Losses. Chemistry of Materials 2019, 31 (15), 5450-5463.

38. Cai, W.; Wan, J., Facile Synthesis of Superparamagnetic Magnetite Nanoparticles in Liquid Polyols. Journal of colloid and interface science 2007, 305 (2), 366-370.

39. Pinna, N.; Grancharov, S.; Beato, P.; Bonville, P.; Antonietti, M.; Niederberger, M., Magnetite Nanocrystals: Nonaqueous Synthesis, Characterization, and Solubility. Chemistry of Materials 2005, 17 (11), 3044-3049.

40. Masthoff, M.; Buchholz, R.; Beuker, A.; Wachsmuth, L.; Kraupner, A.; Albers, F.; Freppon, F.; Helfen, A.; Gerwing, M.; Höltke, C., Introducing Specificity to Iron Oxide Nanoparticle Imaging by Combining 57fe-Based Mri and Mass Spectrometry. Nano Letters 2019, 19 (11), 7908-7917.

41. Weissleder, R. a.; Stark, D. D.; Engelstad, B. L.; Bacon, B. R.; Compton, C. C.; White, D. L.; Jacobs, P.; Lewis, J., Superparamagnetic Iron Oxide: Pharmacokinetics and Toxicity. American Journal of Roentgenology 1989, 152 (1), 167-173.

42. Sangnier, A. P.; Van de Walle, A. B.; Curcio, A.; Le Borgne, R.; Motte, L.; Lalatonne, Y.; Wilhelm, C., Impact of Magnetic Nanoparticle Surface Coating on Their Long-Term Intracellular Biodegradation in Stem Cells. Nanoscale 2019, 11 (35), 16488-16498.

43. Jiang, W.; Kim, B. Y.; Rutka, J. T.; Chan, W. C., Nanoparticle-Mediated Cellular Response Is SizeDependent. Nature nanotechnology 2008, 3 (3), 145-150.

44. Martina, M.-S.; Wilhelm, C.; Lesieur, S., The Effect of Magnetic Targeting on the Uptake of Magnetic-Fluid-Loaded Liposomes by Human Prostatic Adenocarcinoma Cells. Biomaterials 2008, 29 (30), 4137-4145.

45. Espinosa, A.; Reguera, J.; Curcio, A.; Muñoz-Noval, Á.; Kuttner, C.; Van de Walle, A.; Liz-Marzán, L. M.; Wilhelm, C., Janus Magnetic-Plasmonic Nanoparticles for Magnetically Guided and Thermally Activated Cancer Therapy. Small 2020, 16 (11), 1904960.

46. Van de Walle, A.; Faissal, W.; Wilhelm, C.; Luciani, N., Role of Growth Factors and Oxygen to Limit Hypertrophy and Impact of High Magnetic Nanoparticles Dose During Stem Cell Chondrogenesis. Computational and structural biotechnology journal 2018, 16, 532-542.

47. Espinosa, A.; Kolosnjaj-Tabi, J.; Abou-Hassan, A.; Plan Sangnier, A.; Curcio, A.; Silva, A. K.; Di Corato, R.; Neveu, S.; Pellegrino, T.; Liz-Marzán, L. M.; Wilhelm, C., Magnetic (Hyper) Thermia or Photothermia? Progressive Comparison of Iron Oxide and Gold Nanoparticles Heating in Water, in Cells, and in Vivo. Advanced Functional Materials 2018, 28 (37), 1803660.

48. Zyuzin, M. V.; Cassani, M.; Barthel, M. J.; Gavilan, H.; Silvestri, N.; Escudero, A.; Scarpellini, A.; Lucchesi, F.; Teran, F. J.; Parak, W. J., Confining Iron Oxide Nanocubes inside Submicrometric Cavities as a Key Strategy to Preserve Magnetic Heat Losses in an Intracellular Environment. ACS applied materials \& interfaces 2019, 11 (45), 41957-41971.

49. Espinosa, A.; Silva, A. K.; Sánchez-Iglesias, A.; Grzelczak, M.; Péchoux, C.; Desboeufs, K.; LizMarzán, L. M.; Wilhelm, C., Cancer Cell Internalization of Gold Nanostars Impacts Their Photothermal Efficiency in Vitro and in Vivo: Toward a Plasmonic Thermal Fingerprint in Tumoral Environment. Advanced healthcare materials 2016, 5 (9), 1040-1048.

50. Sangnier, A. P.; Van de Walle, A. B.; Aufaure, R.; Fradet, M.; Motte, L.; Guenin, E.; Lalatonne, Y.; Wilhelm, C., Endosomal Confinement of Gold Nanospheres, Nanorods and Nanoraspberries Governs Their Photothermal Identity and Is Beneficial for Cancer Cells Therapy. Advanced Biosystems 2020. 
51. Di Corato, R.; Gazeau, F.; Le Visage, C.; Fayol, D.; Levitz, P.; Lux, F.; Letourneur, D.; Luciani, N.; Tillement, O.; Wilhelm, C., High-Resolution Cellular Mri: Gadolinium and Iron Oxide Nanoparticles for in-Depth Dual-Cell Imaging of Engineered Tissue Constructs. ACS nano 2013, 7 (9), 7500-7512.

52. Sharifi, S.; Seyednejad, H.; Laurent, S.; Atyabi, F.; Saei, A. A.; Mahmoudi, M., Superparamagnetic Iron Oxide Nanoparticles for in Vivo Molecular and Cellular Imaging. Contrast media \& molecular imaging 2015, 10 (5), 329-355.

53. Smirnov, P.; Poirier-Quinot, M.; Wilhelm, C.; Lavergne, E.; Ginefri, J. C.; Combadière, B.; Clément, O.; Darrasse, L.; Gazeau, F., In Vivo Single Cell Detection of Tumor-Infiltrating Lymphocytes with a Clinical 1.5 Tesla Mri System. Magnetic Resonance in Medicine: An Official Journal of the International Society for Magnetic Resonance in Medicine 2008, 60 (6), 1292-1297.

54. Kolosnjaj-Tabi, J.; Wilhelm, C.; Clément, O.; Gazeau, F., Cell Labeling with Magnetic Nanoparticles: Opportunity for Magnetic Cell Imaging and Cell Manipulation. Journal of nanobiotechnology 2013, 11 (1), 1-19.

55. Mazuel, F.; Espinosa, A.; Luciani, N.; Reffay, M.; Le Borgne, R.; Motte, L.; Desboeufs, K.; Michel, A.; Pellegrino, T.; Lalatonne, Y.; Wilhelm, C., Massive Intracellular Biodegradation of Iron Oxide Nanoparticles Evidenced Magnetically at Single-Endosome and Tissue Levels. ACS nano 2016, 10 (8), 7627-7638.

56. Du, V.; Luciani, N.; Richard, S.; Mary, G.; Gay, C.; Mazuel, F.; Reffay, M.; Menasche, P.; Agbulut, O.; Wilhelm, C., A 3d Magnetic Tissue Stretcher for Remote Mechanical Control of Embryonic Stem Cell Differentiation. Nature communications 2017, 8 (1), 1-12.

57. Fayol, D.; Frasca, G.; Le Visage, C.; Gazeau, F.; Luciani, N.; Wilhelm, C., Use of Magnetic Forces to Promote Stem Cell Aggregation During Differentiation, and Cartilage Tissue Modeling. Advanced Materials 2013, 25 (18), 2611-2616.

58. Shimizu, K.; Ito, A.; Lee, J. K.; Yoshida, T.; Miwa, K.; Ishiguro, H.; Numaguchi, Y.; Murohara, T.; Kodama, I.; Honda, H., Construction of Multi-Layered Cardiomyocyte Sheets Using Magnetite Nanoparticles and Magnetic Force. Biotechnology and bioengineering 2007, 96 (4), 803-809.

59. Zwi-Dantsis, L.; Wang, B.; Marijon, C.; Zonetti, S.; Ferrini, A.; Massi, L.; Stuckey, D. J.; Terracciano, C. M.; Stevens, M. M., Remote Magnetic Nanoparticle Manipulation Enables the Dynamic Patterning of Cardiac Tissues. Advanced Materials 2020, 32 (6), 1904598.

60. Frasca, G.; Gazeau, F.; Wilhelm, C., Formation of a Three-Dimensional Multicellular Assembly Using Magnetic Patterning. Langmuir 2009, 25 (4), 2348-2354.

61. Souza, G. R.; Molina, J. R.; Raphael, R. M.; Ozawa, M. G.; Stark, D. J.; Levin, C. S.; Bronk, L. F.; Ananta, J. S.; Mandelin, J.; Georgescu, M.-M., Three-Dimensional Tissue Culture Based on Magnetic Cell Levitation. Nature nanotechnology 2010, 5 (4), 291-296.

62. Mejías, R.; Gutiérrez, L.; Salas, G.; Pérez-Yagüe, S.; Zotes, T. M.; Lázaro, F. J.; Morales, M. P.; Barber, D. F., Long Term Biotransformation and Toxicity of Dimercaptosuccinic Acid-Coated Magnetic Nanoparticles Support Their Use in Biomedical Applications. Journal of Controlled Release 2013, 171 (2), 225-233.

63. Rojas, J. M.; Gavilán, H.; del Dedo, V.; Lorente-Sorolla, E.; Sanz-Ortega, L.; da Silva, G. B.; Costo, R.; Perez-Yagüe, S.; Talelli, M.; Marciello, M., Time-Course Assessment of the Aggregation and Metabolization of Magnetic Nanoparticles. Acta biomaterialia 2017, 58, 181-195.

64. Stepien, G.; Moros, M.; Pérez-Hernández, M.; Monge, M.; Gutiérrez, L.; Fratila, R. M.; Las Heras, M. d.; Menao Guillén, S. n.; Puente Lanzarote, J. J.; Solans, C., Effect of Surface Chemistry and Associated Protein Corona on the Long-Term Biodegradation of Iron Oxide Nanoparticles in Vivo. ACS applied materials \& interfaces 2018, 10 (5), 4548-4560.

65. Liu, G.; Gao, J.; Ai, H.; Chen, X., Applications and Potential Toxicity of Magnetic Iron Oxide Nanoparticles. Small 2013, 9 (9-10), 1533-1545.

66. Sabella, S.; Carney, R. P.; Brunetti, V.; Malvindi, M. A.; Al-Juffali, N.; Vecchio, G.; Janes, S. M.; Bakr, O. M.; Cingolani, R.; Stellacci, F., A General Mechanism for Intracellular Toxicity of MetalContaining Nanoparticles. Nanoscale 2014, 6 (12), 7052-7061. 
67. Levy, M.; Lagarde, F.; Maraloiu, V.-A.; Blanchin, M.-G.; Gendron, F.; Wilhelm, C.; Gazeau, F., Degradability of Superparamagnetic Nanoparticles in a Model of Intracellular Environment: Follow-up of Magnetic, Structural and Chemical Properties. Nanotechnology 2010, 21 (39), 395103.

68. Lartigue, L.; Alloyeau, D.; Kolosnjaj-Tabi, J.; Javed, Y.; Guardia, P.; Riedinger, A.; Péchoux, C.; Pellegrino, T.; Wilhelm, C.; Gazeau, F., Biodegradation of Iron Oxide Nanocubes: High-Resolution in Situ Monitoring. Acs Nano 2013, 7 (5), 3939-3952.

69. Mazuel, F.; Espinosa, A.; Radtke, G.; Bugnet, M.; Neveu, S.; Lalatonne, Y.; Botton, G. A.; AbouHassan, A.; Wilhelm, C., Magneto-Thermal Metrics Can Mirror the Long-Term Intracellular Fate of Magneto-Plasmonic Nanohybrids and Reveal the Remarkable Shielding Effect of Gold. Advanced Functional Materials 2017, 27 (9), 1605997.

70. Boitard, C.; Curcio, A.; Rollet, A.-L.; Wilhelm, C.; Ménager, C.; Griffete, N., Biological Fate of Magnetic Protein-Specific Molecularly Imprinted Polymers: Toxicity and Degradation. ACS applied materials \& interfaces 2019, 11 (39), 35556-35565.

71. Aisen, P.; Wessling-Resnick, M.; Leibold, E. A., Iron Metabolism. Current opinion in chemical biology 1999, 3 (2), 200-206.

72. López-Castro, J. D.; Maraloiu, A. V.; Delgado, J.; Calvino, J.; Blanchin, M.-G.; Gálvez, N.; Domínguez-Vera, J. M., From Synthetic to Natural Nanoparticles: Monitoring the Biodegradation of Spio (P904) into Ferritin by Electron Microscopy. Nanoscale 2011, 3 (11), 4597-4599.

73. Hohnholt, M. C.; Geppert, M.; Luther, E. M.; Petters, C.; Bulcke, F.; Dringen, R., Handling of Iron Oxide and Silver Nanoparticles by Astrocytes. Neurochemical research 2013, 38 (2), 227-239.

74. Tamion, A.; Hillenkamp, M.; Hillion, A.; Maraloiu, V. A.; Vlaicu, I. D.; Stefan, M.; Ghica, D.; Rositi, H.; Chauveau, F.; Blanchin, M.-G., Ferritin Surplus in Mouse Spleen 14 Months after Intravenous Injection of Iron Oxide Nanoparticles at Clinical Dose. Nano Research 2016, 9 (8), 2398-2410.

75. Gutiérrez, L.; Lázaro, F. J.; Abadía, A. R.; Romero, M. S.; Quintana, C.; Morales, M. P.; Patino, C.; Arranz, R., Bioinorganic Transformations of Liver Iron Deposits Observed by Tissue Magnetic Characterisation in a Rat Model. Journal of inorganic biochemistry 2006, 100 (11), 1790-1799.

76. Ruiz, A.; Gutiérrez, L.; Cáceres-Vélez, P.; Santos, D.; Chaves, S. B.; Fascineli, M. L.; García, M. P.; Azevedo, R.; Morales, M., Biotransformation of Magnetic Nanoparticles as a Function of Coating in a Rat Model. Nanoscale 2015, 7 (39), 16321-16329.

77. Quintana, C.; Cowley, J.; Marhic, C., Electron Nanodiffraction and High-Resolution Electron Microscopy Studies of the Structure and Composition of Physiological and Pathological Ferritin. Journal of structural biology 2004, 147 (2), 166-178.

78. Wong, K. K.; Douglas, T.; Gider, S.; Awschalom, D. D.; Mann, S., Biomimetic Synthesis and Characterization of Magnetic Proteins (Magnetoferritin). Chemistry of materials 1998, 10 (1), 279-285. 79. Gilder, S. A.; Wack, M.; Kaub, L.; Roud, S. C.; Petersen, N.; Heinsen, H.; Hillenbrand, P.; Milz, S.; Schmitz, C., Distribution of Magnetic Remanence Carriers in the Human Brain. Scientific reports 2018, $8(1), 1-9$.

80. Khan, S.; Cohen, D., Using the Magnetoencephalogram to Noninvasively Measure Magnetite in the Living Human Brain. Human brain mapping 2019, 40 (5), 1654-1665.

81. Liu, J.-L.; Fan, Y.-G.; Yang, Z.-S.; Wang, Z.-Y.; Guo, C., Iron and Alzheimer's Disease: From Pathogenesis to Therapeutic Implications. Frontiers in neuroscience 2018, 12, 632.

82. Calderón-Garcidueñas, L.; González-Maciel, A.; Mukherjee, P. S.; Reynoso-Robles, R.; PérezGuillé, B.; Gayosso-Chávez, C.; Torres-Jardón, R.; Cross, J. V.; Ahmed, I. A.; Karloukovski, V. V., Combustion-and Friction-Derived Magnetic Air Pollution Nanoparticles in Human Hearts. Environmental research 2019, 176, 108567.

83. Lu, D.; Luo, Q.; Chen, R.; Zhuansun, Y.; Jiang, J.; Wang, W.; Yang, X.; Zhang, L.; Liu, X.; Li, F., Chemical Multi-Fingerprinting of Exogenous Ultrafine Particles in Human Serum and Pleural Effusion. Nature communications 2020, 11 (1), 1-8.

84. Murros, K.; Wasiljeff, J.; Macías-Sánchez, E.; Faivre, D.; Soinne, L.; Valtonen, J.; Pohja, M.; Saari, P.; Pesonen, L. J.; Salminen, J. M., Magnetic Nanoparticles in Human Cervical Skin. Frontiers in medicine 2019, 6, 123. 
85. Elfick, A.; Rischitor, G.; Mouras, R.; Azfer, A.; Lungaro, L.; Uhlarz, M.; Herrmannsdörfer, T.; Lucocq, J.; Gamal, W.; Bagnaninchi, P., Biosynthesis of Magnetic Nanoparticles by Human Mesenchymal Stem Cells Following Transfection with the Magnetotactic Bacterial Gene Mms6. Scientific reports 2017, 7, 39755.

86. Wang, C. X.; Hilburn, I. A.; Wu, D.-A.; Mizuhara, Y.; Cousté, C. P.; Abrahams, J. N.; Bernstein, S. E.; Matani, A.; Shimojo, S.; Kirschvink, J. L., Transduction of the Geomagnetic Field as Evidenced from Alpha-Band Activity in the Human Brain. eneuro 2019.

87. Wiltschko, R., Magnetic Orientation in Animals. Springer Science \& Business Media: 2012; Vol. 33. 